\title{
Exploration and Practice of Excellent Marine Meteorology Talents Training
}

\author{
Lingli Fan \\ School of ocean and meteorology \\ Guangdong Ocean University \\ Zhanjiang, China \\ fanlingli@126.com
}

\author{
Guangya Zhang* \\ Dean's office \\ Guangdong Ocean University \\ Zhanjiang, China \\ *Corresponding author, zhangguangya@126.com
}

\begin{abstract}
In order to adapt to the demand of new situation for meteorology talents training in universities. Guangdong Ocean University relying on its own advantages carried out the exploration and practice of marine meteorology talents training. Guangdong Ocean University marine meteorology talents training appreciated by the society and employers, because of following characteristics: the organic combination of marine and atmospheric science; defining the training target of marine characteristic meteorology talents, setting up a curriculum system to support the talents training goal, endowing the traditional atmospheric science with distinctive marine features; building innovation and entrepreneurship education curriculum system, strengthening teachers' innovation and entrepreneurship education teaching ability, cultivating students' independent thinking and rational judgment, and the rate of admission for graduate students is high; strengthening the construction of laboratories and off campus practice bases, carrying out marine meteorological observation by scientific research ship.
\end{abstract}

Keywords-Meteorology talents; With marine characteristics; interdisciplinary; Talents training

\section{INTRODUCTION}

A. It is a requirement for Guangdong to build up a strong marine province by speeding up the training of innovative and pioneering atmosphere talents with marine characteristics

21 Century is the century of marine development and protection[1]. It is the demand of the times to build a remarkable marine talents team. Guangdong is a major province of marine economy[2], but the marine innovation capability and overall competitiveness need to be improved[3]. It is necessary to promote marine observation and monitoring, forecasting, emergency response, marine information and other marine public service capabilities, improve the marine public service system, and provide the necessary support for marine economic development. Our school is adjacent to the South China Sea(SCS). The research and development of SCS has a unique geographical advantage.

\section{B. requirement for the training of meteorological talents}

Under the background of climate change, the society's demand for meteorological disaster prevention and reduction, climate change is becoming more and more vigorous. China Meteorological Administration regards the development of marine meteorology as the primary development strategy. To establish a comprehensive observation system for marine meteorology, and a marine meteorological forecast and early warning service system in SCS. This work will require many marine meteorological talents.

\section{A requirement for the characteristic development of Guangdong Ocean university}

There are more than ten universities in China with atmospheric science majors, and some universities have a long history[4]. The undergraduate course of Atmospheric Science in our university has been approved for enrollment in 2006.Relying on the advantages of discipline, cultivate new growth points, focus on scientific issues of atmosphere and ocean cross field. It is in line with the development strategy of our school to cultivate innovative and practical talents with innovative ability and practical ability. It is also a short cut for the specialty of atmospheric science[5].

\section{A requirement for improving the competitiveness of our graduates}

Broaden the direction of atmospheric science development, and set up marine meteorological characteristics of professional direction, can strengthen the competitiveness of our graduates.

\section{SOLVING THE MAIN PROBLEMS IN TEACHING}

How can local universities rely on the advantages of disciplines to conduct interdisciplinary studies and cultivate new growth points in their profession?

Explore the ways to train talents in universities to meet the needs of the national development strategy, local economic development, industry talent demand, school characteristic development and students' development needs.

Through the optimization of the curriculum system, the traditional atmospheric science will be endowed with distinctive marine features.

By strengthening the basic courses, inquiry learning, scientific research and training, and other ways are taken to cultivate students' innovative ability.

Strengthening construction of meteorological observation Laboratory, weather forecast laboratory, air sea interaction laboratory; strengthening students' extracurricular practice base 
construction; make full use of the advantages of marine science and carry out marine meteorological observation by scientific research ship. Students adhere to long-term meteorological observation independent practice, sharpen the students "Three Capabilities” quality[6], " Marine features", cultivate the entrepreneurial ability in their job.

\section{SOLUTIONS AND PRACTICE TO PROBLEMS}

A. According to the local economy, industry talent demand, university management goal and talent training target, we should adhere to the ability to teach students in accordance with their aptitude, train them in various levels, and pay special attention to cultivate innovative and pioneering talents with marine features

Relying on "Quality engineering" construction project of Guangdong provincial education department in 2014(pilot reform of Marine Meteorology talents training mode), consulting with the meteorological departments at various levels, making scientific personnel training program and optimizing curriculum system. Our team makes the teaching contents of all courses link up each other, form a system, and constantly strengthen the goal of each link in talent training. Our team adheres to the concept of individualized training, establish a multi-level talent training model, focusing on the foundation and respecting choice. To promote the reform of personnel training mode, that is "low grade of general education, professional education of wide caliber in high grade, credit system and independent choice of development plan", gradually achieve the goal of cultivating distinctive talents with distinctive marine features.

\section{B. Optimize the curriculum system, strengthen marine} features, strengthen students' ability to innovate and entrepreneurship, and formulate personnel training programs

Our team focuses on the construction of curriculum system which aimed at strengthening the basic, improving the quality and promoting the cross. The curriculum system includes five basic courses, basic course, specialized basic course, specialized direction course, specialized development course, general education course (including innovation and Entrepreneurship). According to the characteristics of the cross discipline of ocean and atmosphere, research course, practice and practice course of incentive innovation are increased, which lays a solid curriculum foundation for the cultivation of innovative talents.

In accordance with the requirements of Chinese Ministry of Education, and to meet the requirements of the modernization development of China Meteorology Administration, atmospheric science department has constantly adjusted and perfected the curriculum system [7]. Added public elective courses, such as "Introduction to Oceanography", "physical oceanography", added other professional courses, such as the" Marine Meteorology ", added other professional optional courses, such as "marine investigation and monitoring technology ","storm surge"[8]. We constantly update the course content, the curriculum content can reflect the latest research progress of atmospheric science, marine science. The curriculum construction and the development of the industry combined to further promote the reform of teaching [9]. To train more students engaged in marine meteorological exploration, forecasting and disaster warning, and to meet the needs of the modern meteorological service put forward by the China Meteorological administration [10].

Gradually optimize the talent training program, social satisfaction continues to improve. In order to adapt to the catalogue of national undergraduate professional adjustment, improve the quality of personnel training, enhance the ability of graduates to adapt to the development of economic society and industry, Department of Atmospheric Sciences conducted extensive research, invited industry experts, graduate students to participate in the training plan revision work. After the two adjusting in 2009 and 2013 version, its structure, content system is more optimized, marine characteristics more prominent, innovation and entrepreneurship training system is more perfect. The combination of innovation, entrepreneurship education and professional education runs through the process of talent training. Some undergraduate students have achieved success in scientific research, showing a good potential for Innovation: students have declared 16 for innovation and entrepreneurship, approved 13 projects, 70 students attended, 4 papers had published. About 50 students have been enrolled in high-level universities and research institutes since 2010, and the rate of entrance examinations for postgraduates is about $10 \%$.

Strengthen the foundation and broaden the caliber. Enrich the general education curriculum, broaden the subject basic courses, strengthen the higher mathematics and physics course, and improve the innovation and entrepreneurship training system. The proportion of general education, subject foundation and professional basic courses should be increased to $70 \%$, and the basic knowledge of students should be consolidated and the comprehensive quality of students should be improved. Combined with the development needs of the meteorological industry, interdisciplinary between disciplines, setting professional direction or series of curriculum modules, such as: marine monitoring, disaster weather warning, lightning monitoring and protection and other courses, which enhances the adaptability and flexibility of students' development.

Strengthen practice and be good at innovation. Constructing a hierarchical practical teaching system which consisting of basic, comprehensive and innovative practice links. Increasing the proportion of practice teaching to more than $30 \%$, ensure the continuous line of training students' practical ability. By increasing the proportion of comprehensive, designing and research courses, innovative education and innovative practice courses are set up, which strengthens the cultivation of students' innovative consciousness and ability. Constantly practice teaching and training, so that graduates get outstanding performance in their jobs.

Broaden horizons and work hard to start a business. Offering professional foreign language, industry (enterprise) management, industry laws and regulations, professional introduction and other general education optional courses, 
broaden the horizons of students. Flexibly set up the professional direction to meet the needs of economic society and industry. Take professional courses, introduction of marine course, course of ideological and political theory education, curriculum practice, production practice, graduation practice and practice of independent innovation and entrepreneurship practice as the carrier, cultivating students' marine spirit and to devote themselves to marine meteorology, cultivating students' determination to serve the motherland. So that students feel at ease in the grassroots meteorological stations, based on positions, hard-working, entrepreneurship in post.

\section{Strengthen the construction of teaching staff and promote the cultivation of innovative and talented personnel with a high level of teaching}

Through the teaching reform and incentive mechanism to mobilize teachers' teaching enthusiasm, Guangdong Ocean University is organizing many professional/ curriculum construction/teaching ability trainings. Some teachers should be sent to relevant universities for further study and training, and some team members should be arranged to carry out training and study at various levels meteorological departments, to strengthen the training of teachers' teaching ability. Through a variety of ways to make our teachers love teaching, care for students, teachers and students more closely together, further strengthen the teachers' personalized guidance for students, and promote the interaction between teachers and students, which benefit teachers as well as students. The core courses use "teacher team + student group" form, guide students in inquiry learning, combined with curriculum content, require students to query and read the latest research papers, regularly organize the literature reading seminar; at the same time with the typical weather and climate anomalies, guide students to actively analyze the reasons, writing papers, in this way, to mobilize the enthusiasm of the students' innovation and entrepreneurship.

The level of teachers has been continuously improved, and the ability of teaching research and teaching reform has been greatly enhanced. Through this mechanism to promote the interaction between teachers and students. Outstanding achievements have been made in the construction of atmospheric science team. The team has approved or completed 12 teaching projects at all levels, guiding students innovative 16 experimental items, 16 papers had published.

\section{Adhere to create a good environment and promote innovation and Entrepreneurship Education}

Through a variety of activities to create a comprehensive development, healthy growth of the environment and atmosphere, and promote innovation and entrepreneurship education for students. Such as university education, professional introduction, visiting the provincial college practice base outside school and youth employment and entrepreneurship training base, hosting the World Meteorological Day activities, the world ocean day activities, Academic Salon, weather forecast video conferences, college students occupation planning contest, students extracurricular academic science and technology work, holding the postgraduate entrance examination experience exchange and mobilization meeting, "Model Star" selection, awarded "alumni scholarship" and so on.

Through organic combination of the first and second classroom, rich and diverse campus culture, practice and innovation, entrepreneurship platform and other channels, students' humanistic quality and practical ability have been comprehensively cultivated. The quality of talent training steadily improved. The biggest beneficiaries of this project are students. In recent years, the proportion of the atmospheric science graduates which enter the domestic and foreign highlevel universities continue to study, is the first in our university. These reflect the overall improvement of undergraduate students in comprehensive quality, professional quality, academic pursuit and research potential.

1) Since 2006, the major of atmospheric science has begun to enroll undergraduates. About 50 students have been enrolled in high-level universities and research institutes, and the rate of entrance examinations for postgraduates is about $10 \%$. The admission rate is over $60 \%$.

2) Some undergraduate students have achieved great success in scientific research, showing a good potential for Innovation: students have declared 16 for innovation and entrepreneurship, approved 13 projects, 70 students attended, 8 papers had published.

3) More than $70 \%$ of graduates enter the Meteorological Bureau and air traffic control station at various levels, and obtain outstanding achievements in their posts. Graduate named Li Huiqing, was awarded the title of "excellent meteorological observer" by the China Meteorological Administration in 2013, Graduate named Zeng Lingyue, was awarded the title of "excellent meteorological forecaster" by Guangdong Meteorological Administration, and so on.

\section{EFFECT AND INFLUENCE OF CASE}

\section{A. The reform is fruitful, widely used and obvious in demonstration}

Atmospheric science talent training program with marine characteristics was approved by experts and graduates unanimously. The Meteorological Laboratories and the practice bases receive many universities peers to visit and investigate; hold many teaching and learning experience exchange activities.

Atmospheric science is a major of comprehensive reform in Guangdong, is a pilot project for the reform of outstanding marine talents training mode. A teacher in atmospheric science department is one member of the steering committee of the atmospheric science department of the Ministry of Education. A teacher in atmospheric science department is one member of teaching supervisor of Guangdong Ocean University. Atmospheric science department has won more than 30 kinds of awards since 2006, approved 12 teaching and research projects, 16 papers had published. 


\section{B. The effect of talent training is remarkable, and is highly praised by social and employers}

Since 2006, atmospheric science department has trained more than 360 graduates, the employment rate remained at $100 \%$, more than $70 \%$ of graduates enter the Meteorological Bureau and air traffic control station at various levels. Employers evaluate our graduates "peace of mind, can bear hardships, can start an undertaking".

The students' innovative ability has obviously increased. In recent years, students have declared 16 projects for innovation and entrepreneurship, and 13 projects have been approved, including 3 national projects and 12 provincial projects, with a total participation of $20 \%$, and 8 papers had published in public.

Graduates gradually become the elite of station observation and prediction, and a group of typical figures emerge, such as: Graduates such as Yao Qiuyun, Zhong Meiying and Zhang Tao were awarded the title of "excellent meteorological observer" by the China Meteorological Administration.

\section{CONCLUSION}

Innovation is the organic combination of marine and atmospheric science. To broaden the development direction of Atmospheric Sciences, comply with the new requirements of the development of meteorological services, in response to the national maritime strategy. Strengthening Guangdong ocean university characteristics.

Defining the training target of marine characteristic innovation and entrepreneurship talents, sets up a curriculum system to support the talents training goal, sets up marine courses reasonably, and endows the traditional atmospheric science with distinctive marine features.

The training mode and teaching method have been reformed. Through inquiry learning and scientific research project-based learning, the students' innovative ability can be raised, and the rate of admission for graduate students is high.

Strengthening the construction of laboratories such as meteorological observation laboratory, weather forecast laboratory, and air sea interaction laboratory; Strengthening the construction of off campus practice bases for Students; make full use of the advantages of marine science and carry out marine meteorological observation by scientific research ship. Students adhere to long-term meteorological observation independent practice, sharpen the students "Three Capabilities" quality, " Marine features", cultivate the entrepreneurial ability in their job.

\section{ACKNOWLEDGMENT}

Fund Projects: Exploration and practice of applied talents of atmospheric science to meet the needs of industry development,2016(263), project supported by college teaching quality and teaching reform project construction project in Guangdong, the Education Department of Guangdong province. Collaborative training platform of atmospheric science specialty based on production, research and teaching, 2016(7513), teaching project of "13th Five-Year" and "quality engineering innovation project" in Guangdong Ocean University. Quality resource sharing: Atmospheric Sounding, 2016(75-23), teaching project of "13th Five-Year" and "quality engineering innovation project" in Guangdong Ocean University.

\section{REFERENCES}

[1] Luo Weiqi. "the speech in the promotion meeting of innovation and entrepreneurship education reform in Guangdong [EB/OL] ," http://www.gdhed.edu.cn/publicfiles/business/htmlfiles/gdjyt/gdjy/2016 04/497516.html,unpublished. (In Chinese)

[2] Hou yuan, "the speech in the promotion meeting of deepening innovation and entrepreneurship education in regional universities," http://jy.imnu.edu.cn/n445c11.jsp,unpublished. (In Chinese)

[3] Liu Yandong, "further promoting the reform and innovation of entrepreneurship education to cultivate public business innovation, in deepening the reform of the innovation and entrepreneurship education in universities forum," [EB/OL],

http://www.moe.edu.cn/jyb_xwfb/moe_176/201510/t20151026_215488. html,unpublished. (In Chinese).

[4] Notice on the publication of the articles of association of Guangdong Ocean University http://www2.gdou.edu.cn/hdwj/2014/d201475.htm.

[5] Constitution of Guangdong Ocean University, http://www2.gdou.edu.cn/hdwj/2014/d201475.htm,unpublished. （In Chinese)

[6] The practice of "three Capabilities " characteristic talent training mode, Higher Agricultural Education, 2009, 03: 42-43 (In Chinese)

[7] Fan Lingli,Zhang Guangya, "Exploration and practice of the application of atmospheric science training talents in multidisciplinary Ocean University,” Marine development and management, 2011,11.

[8] Zhang Guangya, Fan Lingli, An Lilong, "Relying on the advantages of disciplines to optimize the professional structure" Higher Agricultural Education, 2011, 09: 66-69 (In Chinese)

[9] Opinions on strengthening the innovation and entrepreneurship education for undergraduates in Guangdong Ocean University, http://www2.gdou.edu.cn/hdwj/2015/jw2150122.htm,unpublished. (In Chinese)

[10] The work plan of building “Public Entrepreneurship, Innovation” demonstration base in Guangdong Ocean University (2016-2018), http://www2.gdou.edu.cn/hdwj/2016/zsjy2160019.htm ,unpublished. (In Chinese) 